\title{
Asymmetric Stakes in Antitrust Litigation
}

\author{
Erik Hovenkamp \\ University of Southern California School of Law, ehovenkamp@law.harvard.edu \\ Steven C. Salop \\ Georgetown University Law Center, salop@law.georgetown.edu
}

This paper can be downloaded free of charge from:

https://scholarship.law.georgetown.edu/facpub/2250

https://papers.ssrn.com/sol3/papers.cfm?abstract_id=3563843

Erik Hovenkamp \& Steven C. Salop, Asymmetric Stakes in Antitrust Litigation (Mar. 29, 2020)

This open-access article is brought to you by the Georgetown Law Library. Posted with permission of the author. Follow this and additional works at: https://scholarship.law.georgetown.edu/facpub

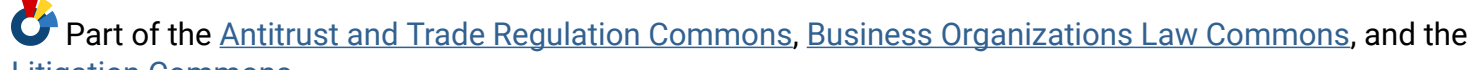
Litigation Commons 


\title{
Asymmetric Stakes in Antitrust Litigation*
}

\author{
Erik Hovenkamp $^{\dagger} \quad$ Steven C. Salop ${ }^{\ddagger}$
}

\begin{abstract}
Private antitrust litigation often involves a dominant firm being accused of exclusionary conduct by a smaller rival or entrant. Importantly, the firms in such cases generally have asymmetric stakes: the defendant typically has a much larger financial interest on the line. We explore the broad policy implications of this fact using a novel model of litigation with endogenous effort. Asymmetric stakes lead dominant defendants to invest systematically more resources into litigation, causing the plaintiff's success probability to fall below the efficient level - a distortion that carries over to ex ante settlements. We explain that enhanced damages may reduce the problem, but cannot eliminate it. We also show that, in most areas of private law, asymmetric stakes do not distort litigation outcomes in this way; the distortion arises in antitrust only because it proscribes certain ex post settlements, and this constraint influences incentives at the litigation stage. Finally, we consider how courts could correct the distortion created by asymmetric stakes by altering plaintiffs' evidentiary burden.
\end{abstract}

*We thank Andrew Gavil and Fiona Scott Morton for helpful discussions.

${ }^{\dagger}$ Assistant Professor, USC Gould School of Law.

${ }^{\ddagger}$ Professor of Economics and Law, Georgetown University Law Center. 


\section{Introduction}

Private antitrust litigation frequently involves a dominant firm being accused of anticompetitive exclusionary conduct by a smaller rival or prospective entrant. A key fact about such disputes, which is independent of the underlying merit of the antitrust claim, is that the defendant typically has a markedly larger financial stake in the outcome of litigation. The dominant firm is looking to protect monopoly profits, while the smaller plaintiff is seeking to maintain a modest position in a more competitive market. The result is that the defendant has an incentive to spend significantly more to thwart the plaintiff's efforts than the latter would pay to maintain a foothold in the marketplace. ${ }^{1}$

For example, suppose a dominant firm is accused of exclusionary conduct by a smaller rival. If the defendant's conduct is allowed to persist, the rival will go out of business, resulting in a monopoly profit of $\$ 100$ for the defendant and no profits for the plaintiff. By contrast, if a court issues an injunction to halt the defendant's conduct, the plaintiff will stay in business and earn $\$ 15$ through ordinary competition, while the defendant will earn $\$ 55$. As these numbers reflect, monopoly — whether obtained through anticompetitive conduct or a procompetitieve efficiency - typically generates larger total profits than competition. The result is that the defendant must have a larger stake in the outcome of litigation. ${ }^{2}$ For instance, on these numbers, the plaintiff stands to gain $\$ 15$ by winning, while the defendant stands to gain $\$ 45$ if the plaintiff's claim fails. ${ }^{3}$

In this paper we examine the broad implications of asymmetric stakes for antitrust policy and enforcement. We develop a novel model of litigation with endogenous effort, meaning that each firm can choose how much resources to invest in litigation in order to influence its chances of prevailing. One of our key initial results is that the asymmetry leads dominant defendants to invest significantly more in litigation, resulting in the plaintiff's winning probability being biased; that is, the plaintiff's winning probability is strictly lower than the normatively optimal level, as determined by the merits of its complaint. The result is that litigation outcomes are systematically distorted in defendants' favor. This undermines deterrence of anticompetitive practices. Moreover, while enhanced damages can help to reduce the extent of the problem, they can never eliminate it.

In our model, a court renders a final decision based on a noisy signal that depends on both: (a) the underlying merit of the plaintiff's complaint, which can range from very strong to

\footnotetext{
${ }^{1}$ An analogous disparity was studied in the context of R\&D competition in Gilbert and Newbery (1982).

${ }^{2}$ The asymmetry will be even larger if the plaintiff's victory would also facilitate entry by third parties.

${ }^{3}$ Damages would not change this conclusion, as they are just a one-to-one transfer between the firms.
} 
very weak; and (b) the firms' choices of how much to invest in litigation. When the firms invest equal amounts, the signal is unbiased, and hence the plaintiff's winning probability is entirely commensurate with the merit of its complaint. But when the firms invest different amounts - as they always do in equilibrium - the probability will always be biased away from the optimal level, favoring the firm who spent more.

Consideration of endogenous effort in litigation is particularly apropos in the antitrust context, where discovery is often very broad-sweeping and complex and the parties spend large amounts on economic consultants and expert witnesses for both liability and damages. Economic evidence plays a significant role in the outcome, and the parties can spend an enormous amount on econometric studies and simulation models, and on rigorous critiques of each other's analyses. The judge, meanwhile, is unlikely to be well-versed in the relevant economic issues and methodologies. This means that a firm's spending on economic experts can be very fruitful, for the court is likely to rely heavily on the parties' experts to understand the complexities of the case.

We also analyze the interplay between asymmetric stakes and settlement. We show that, in most other areas of private litigation, asymmetric stakes do not lead to any inefficient distortion in the equilibrium probability that the plaintiff will prevail; this result is very general and occurs because of the way that the prospect of ex post (post-judgment) settlement influences incentives at the litigation stage. But antitrust law generally prohibits otherwise-profitable settlements in which a losing defendant pays the plaintiff for the right to continue a practice that has just been declared anticompetitive. As a result, the prospect of ex post settlement does not prevent the firms' asymmetric stakes from distorting litigation outcomes in equilibrium. We further consider ex ante (pre-judgment) settlements, and show that the distortion created by asymmetric stakes translates into settlement outcomes that are less competitive than they ideally would be.

As we show, one way to countervail the distortion created by asymmetric stakes is to modify the plaintiff's evidentiary burden. We do this by considering judicial reliance on presumptions, which act to predispose the court toward one outcome or the other. We compute the optimal presumption, which may be influenced in part based on the court's priors about the nature of the defendant's conduct-namely, its propensity to cause anticompetitive effects. Finally, we consider whether the problem of asymmetric stakes can be avoided when the plaintiff is a class of injured consumers. However, based on certain externality and principal-agent problems, we conclude that the asymmetry is likely to persist in these cases.

The remainder of the article is organized as follows: following a review of related literature, 
Section 2 formulates the model, explores its properties and shows why damages are unlikely to correct the bias in trial outcomes. Section 3 analyzes settlements. Section 4 shows how the bias can be corrected by adjusting the evidentiary standard with a corrective presumption. Finally, Section 5 considers extensions involving class action litigation and fee shifting.

\subsection{Related Literature}

Our analysis contributes to the literature on the economics of private litigation. Cooter and Rubinfeld (1989) and Spier (2007) discuss some of the major issues in this literature. While some papers give special attention to inter-party asymmetries, the most common one by far is an asymmetry between the parties' beliefs about who is more likely to win, which is an important factor in determining whether the parties will settle (e.g. Priest and Klein, 1984; Waldfogel, 1998; Lee and Klerman, 2016). Some papers make litigation effort endogenous, in which case the parties' investments can be modeled as a game (e.g. Choi and Sanchirico, 2004). However, such papers typically do not focus on any particular field of law, whereas our analysis incorporates various phenomena that are specific to antitrust.

The asymmetric stakes in inter-competitor antitrust litigation arise because it is more profitable to preserve monopoly power than to invigorate competition. In their seminal paper, Gilbert and Newbery (1982) considered the same profit disparity in the context of R\&D competition. By contrast, we explore its impact on antitrust enforcement via litigation with endogenous effort, which similarly involves a kind of investment game between rivals.

A large body of antitrust writing focuses on the relative social costs associated with different kinds of judicial errors (false negatives versus false positives) in antitrust litigation (e.g. Schwartz, 1979; Evans and Padilla, 2005). Easterbrook (1984) famously argued that antitrust standards should embody a strong preference for erring on the side of false negatives (mistaken acquittals); the given rationale is that markets will typically correct these errors organically over time. However, many authors dispute the correctness of this argument and its core premises (e.g. Devlin and Jacobs, 2010; Baker, 2015). Similarly, many papers argue that antitrust's prevailing standards for dealing with exclusionary practices by dominant firms are broadly inadequate (e.g. Salop, 2005; Federico et al., 2020; Gavil and Salop, 2020). This debate is timely in light of the current legislative efforts to reform monopolization law, including Senator Amy Klobuchar's recently introduced bill, which would create anticompetitive presumptions and reduce the enforcement agencies' (but not private plaintiffs') burden 
of proof in monopolization cases. ${ }^{4}$

There are numerous theoretical papers on antitrust that relate to ours. Schwartz and Wickelgren (2011) addresses the efficacy of private antitrust litigation between rivals in curtailing undesirable exclusionary practices. While we discuss deterrence in Section 2.3, our focus is primarily on the inefficiencies created by asymmetric stakes when litigation effort is endogenous. Choi and Spier (2019) consider the ability of class action litigation to deter collusive behavior, which we address in the context of excluionary conduct in Section 5. There are many papers addressing antitrust restrictions on settlement. ${ }^{5}$ Although these focus mainly on IP settlements, the arguments are often analogous.

Many papers attempt to derive various optimal legal standards by relying in part on Bayesian inference, such as Kaplan (1967), Posner (1998), Ayres and Nalebuff (2015), and Salop (2015). ${ }^{6}$ In Section 4, we similarly rely on Bayesian inference in considering judicial reliance on presumptions to modify plaintiffs' evidentiary burden.

\section{Model}

In this section, we introduce our baseline game of litigation with endogenous effort and derive the equilibrium. There are two competing firms, $i=1,2$. Firm 2 (the defendant) is a dominant firm that is being sued by firm 1 , who is a smaller rival (or a prospective entrant). Firm 1 is alleging that firm 2 is engaging in an exclusionary practice (e.g. exclusive dealing, tying, or acquisitions of critical input suppliers). Firm 2's conduct generates a change $w$ in consumer welfare. The interpretation is that the defendant's conduct is anticompetitive (and therefore unlawful under antitrust's consumer welfare standard) if $w<0$, but procompetitive if $w \geq 0$. We assume that the value of $w$ is common knowledge as between the firms, but cannot be directly observed by any third parties, such as judges or antitrust authorities.

At the outset of litigation, we assume the two firms make simultaneous choices of litigation expenditures, denoted $x_{i} \geq 0$ for each firm $i .^{7}$ Each litigant must choose the number and

\footnotetext{
${ }^{4}$ The proposed bill is entitled the "Anticompetitive Exclusionary Conduct Prevention Act of 2020."

${ }^{5}$ See, e.g., Meurer (1989); Shapiro (2003); Edlin et al. (2015); Hovenkamp (2018); Hovenkamp and Lemus (2019). See also Friedman and Wickelgren (2008) for a more general discussion of how private settlements may sometimes countervail substantive policy interests.

${ }^{6}$ See also Kaplow (2011), which considers a non-Bayesian notion of optimal proof burdens.

${ }^{7}$ In practice, one expects that there is some bare-minimum cost $c_{i}>0$ that a litigant must incur, although it may opt to make an additional discretionary expenditure $x_{i}$ to improve its chances. However, we normalize $c_{1}=c_{2}=0$.
} 
quality of attorneys, experts, and consultants it will hire, which will influence the strength of its position in litigation, and $x_{i}$ captures the total cost of those choices. We thus interpret $x_{i}$ as a measure of firm $i$ 's endogenous effort in litigation; all else being equal, an increase in $x_{i}$ will increase its probability of winning the case.

If the court could directly observe the consumer welfare effect $w$, then there would be no risk of errors in litigation outcomes: the court would correctly condemn every anticompetitive practice, while also correctly condoning every efficient one. However, due to imperfect information and the complexities of antitrust subject matter, this is not possible. Instead, we assume that the court observes only a stochastic signal (a noisy estimate) of $w$, given by

$$
y \sim \Phi(\cdot \mid \mathbf{x}, w)
$$

That is, $y$ is drawn from a signal distribution $\Phi$ that depends on both the true welfare effect $w$ and the strategy profile $\mathbf{x}=\left(x_{1}, x_{2}\right)$. However, the court does not observe $w$ or $\mathbf{x}$; it observes only the noisy signal $y$, which it relies upon as its estimate of $w$. Accordingly, the court rules in the plaintiff's favor if $y<0$ and in the defendant's favor if $y \geq 0$.

In this way, the court renders a decision by relying on the signal $y$ as if it is an unbiased estimate in the sense that $\mathbb{E}[y \mid \mathbf{x}, w]=w$, although this is not necessarily true. We assume for now that, if the signal is biased $(\mathbb{E}[y \mid \mathbf{x}, w] \neq w)$, this is attributable solely to asymmetric litigation expenditures. That is, $\Phi$ is in general biased, but it reduces to an unbiased distribution in the symmetric case $x_{1}=x_{2}$. Further, we assume that such bias always favors the firm that spends more. These points are captured by the following pair of assumptions, which also provide intuitive and tractable comparative statics.

Assumption 1. $\Phi$ obeys the relation

$$
\Phi(y \mid \mathbf{x}, w)=\frac{F(y \mid w) x_{1}}{F(y \mid w) x_{1}+[1-F(y \mid w)] x_{2}},
$$

where $F(y \mid w)$ is a cumulative distribution function with density $f(y \mid w) \equiv \partial F(y \mid w) / \partial y$ and support $\mathbb{R}^{8}$

\footnotetext{
${ }^{8}$ Technically condition (1) is undefined when $x_{1}=x_{2}=0$. But note that $\Phi=F$ whenever $x_{1}=x_{2}>0$. Thus, we may naturally assume that $\Phi=F$ when $x_{1}=x_{2}=0$ as well. But this is ultimately irrelevant, as the firms will always choose $x_{1}, x_{2}>0$ in equilibrium.
} 
Assumption 2. $f(y \mid w)$ is symmetric about $w$ and depends only on the difference $|y-w| .^{9}$

The proposition below describes several important implications of these assumptions. (All omitted proofs are in the Appendix.)

Proposition 1. $\Phi$ has the following properties:

(i) $\mathbb{E}[y \mid \mathbf{x}, w]=w$ if and only if $x_{1}=x_{2}$.

(ii) $\Phi\left(y \mid \mathbf{x}^{\prime}, w\right)<\Phi(y \mid \mathbf{x}, w)$ if and only if $x_{2}^{\prime} / x_{1}^{\prime}>x_{2} / x_{1}$.

(iii) $\Phi\left(y \mid \mathbf{x}, w^{\prime}\right)<\Phi(y \mid \mathbf{x}, w)$ if and only if $w^{\prime}>w$.

These results capture a number of desirable and intuitive properties, which we now discuss in turn.

Expenditure-driven bias. Condition $(i)$ states that the signal distribution is unbiased if and only if litigation expenditures are symmetric, because $\Phi$ reduces to an unbiased distribution $F$ when $x_{1}=x_{2}$. By contrast, $\Phi$ skews away from $F$ when expenditures are asymmetric. By condition (ii), this bias always favors the firm who spends more: if firm 2 spends more, then higher values of $y$ become relatively more likely (which benefits firm 2 ), as compared to the symmetric case, whereas the opposite occurs if firm 1 spends more. More concretely, condition (ii) implies that, if $x_{2}^{\prime} / x_{1}^{\prime}>x_{2} / x_{1}$, then $\Phi\left(\cdot \mid \mathbf{x}^{\prime}, w\right)$ is first-order stochastically dominant over $\Phi(\cdot \mid \mathbf{x}, w)$, and vice versa.

Expenditure offset. Condition (ii) also implies that the firms' litigation expenditures offset one another to some extent. This is because condition (ii) implies that $\Phi$ is homogeneous of degree zero with respect to $\mathbf{x}$ : it obeys $\Phi(\cdot \mid \lambda \mathbf{x}, w)=\Phi(\cdot \mid \mathbf{x}, w)$ for any scalar $\lambda>0$. In words, if both expenditures are scaled up or down by a common factor, the distribution is left unchanged.

Dependence on $\boldsymbol{w}$. Finally, condition (iii) says that the true welfare effect $w$ affects the signal distribution independently of $\mathbf{x}$, implying that the underlying merit of the plaintiff's complaint always matters, as one would expect. Specifically, if $w^{\prime}>w$, then $\Phi\left(\cdot \mid \mathbf{x}, w^{\prime}\right)$ first-order stochastically dominates $\Phi(\cdot \mid \mathbf{x}, w)$. Thus, for example, if $w$ is highly negative (corresponding to a highly anticompetitive practice), then the expected value of $y$ will be negative unless firm 2 outspends firm 1 by a sufficiently large amount.

\footnotetext{
${ }^{9}$ The latter condition means that for any $w$ and $w^{\prime}$ we have $f(w-a \mid w)=f\left(w^{\prime}-a \mid w^{\prime}\right)$ for any scalar $a$.
} 


\subsection{Outcome Probabilities and Claim Strength}

We define $\alpha=\alpha(w)$ by

$$
\alpha \equiv F(0 \mid w) .
$$

Thus, $\alpha$ gives the probability that firm 1 will win (conditional on $w$ ) when the signal distribution is unbiased. (Note that $\alpha$ is always interior. ${ }^{10}$ ) We may thus regard $\alpha$ as the normatively optimal winning probability for firm 1 , conditional on $w$. This reflects an assumption that society prefers for courts' decisions to be unbiased. ${ }^{11}$ Further, we can interpret $\alpha$ as a measure of the strength (i.e. merit) of the plaintiff's antitrust claim, since it is inversely related to $w$, which captures the actual consumer welfare effect of the defendant's conduct. Thus, highly anticompetitive practices $(w \ll 0)$ have $\alpha$ close to unity; highly procompetitive practices $(w \gg 0)$ have $\alpha$ close to zero; and close calls $(w \approx 0)$ have $\alpha$ close to $1 / 2$.

Of course, the plaintiff's actual winning probability generally differs from $\alpha$. This probability is given by $p=p(\mathbf{x}, w)$, defined by

$$
p \equiv \Phi(0 \mid \mathbf{x}, w)=\frac{\alpha x_{1}}{\alpha x_{1}+(1-\alpha) x_{2}},
$$

which follows from (1). It is easy to see that the plaintiff's winning probability $p$ deviates from the optimal winning probability $\alpha$ if and only if litigation expenditures are asymmetric, in which case it skews in favor of the firm that spent more. ${ }^{12}$

The functional form of $p$ can be interpreted heuristically in terms of random draws from an urn: suppose that each firm chooses to buy some number of balls to put into an urn; the court will then draw a single ball from the urn and enter judgment for the firm who bought it. The "price" of each ball is exogenously given by $1 / \alpha$ for firm 1 and $1 /(1-\alpha)$ for firm 2. It then follows that $p$ gives the fraction of all balls in the urn that were purchased by firm $1 .{ }^{13}$ This heuristic also highlights the fact that claim strength $\alpha$ governs the relative costs of improving the firms' winning probabilities: when $\alpha$ grows larger, it becomes less

\footnotetext{
${ }^{10}$ This is because $F$ has support $\mathbb{R}$ (Assumption 1 ).

${ }^{11} \mathrm{~A}$ later section considers the possibility that society might want courts to adopt certain presumptions under which the ideal winning probability may deviate from $\alpha$.

${ }^{12}$ This is easiest to see when $\alpha=1 / 2 \Longleftrightarrow p=\frac{x_{1}}{x_{1}+x_{2}}$.

${ }^{13}$ To see this, let $n_{i}$ and $\xi_{i}$ be the number and price of the balls purchased by firm $i$, respectively, where $\xi_{1}=1 / \alpha$ and $\xi_{2}=1 /(1-\alpha)$. Then firm $i$ 's total expenditure is $x_{i}=n_{i} \xi_{i}$, and hence we have

$$
\frac{n_{1}}{n_{1}+n_{2}}=\frac{x_{1} / \xi_{1}}{x_{1} / \xi_{1}+x_{2} / \xi_{2}}=\frac{\alpha x_{1}}{\alpha x_{1}+(1-\alpha) x_{2}}=p .
$$
}


(more) expensive for the plaintiff (defendant) to increase its winning probability by a small increment.

\subsection{Payoffs, Asymmetric Stakes, and Equilibrium}

If firm 1 (the plaintiff) wins, then we assume that firm 2 will be enjoined from engaging in the challenged practice and will have to pay damages of $\delta \geq 0$ to firm 1 . Following the injunction, the resulting market outcome involves duopoly competition with profits of $\pi_{i}^{d}>0$ for each $i$. By contrast, if firm 1 loses, there is no injunction or damages, so firm 2 will continue engaging in the challenged practice without penalty. Given that firm 2 is dominant, we assume that in this case the resulting market outcome involves firm 2 obtaining a monopoly profit of $\pi^{m}$, whereas firm 1 earns no profits because it goes out of business. Such exit by firm 1 does not imply that firm 2's conduct is anticompetitive, however. ${ }^{14}$ Finally, we make the standard assumption that monopoly generates larger total profits than duopoly: $\pi^{m}>\pi_{1}^{d}+\pi_{2}^{d} \cdot{ }^{15}$

Given these profits, we can define the firms' expected payoffs from litigation, which we denote by $u_{i}=u_{i}(\mathbf{x} \mid w)$. These payoffs are given by

$$
\begin{aligned}
u_{1} & =p\left(\pi_{1}^{d}+\delta\right)-x_{1} & u_{2} & =p\left(\pi_{2}^{d}-\delta\right)+(1-p) \pi^{m}-x_{2} \\
& =p v_{1}-x_{1} & & =\pi^{m}-p v_{2}-x_{2},
\end{aligned}
$$

where

$$
v_{1} \equiv \pi_{1}^{d}+\delta, \quad v_{2} \equiv \pi^{m}-\pi_{2}^{d}+\delta
$$

Here $v_{i}$ gives the incremental value to firm $i$ when it wins rather than loses, which captures the firm's financial stake in the outcome of litigation. ${ }^{16}$ Note that $v_{2}>v_{1}$, since $\pi^{m}>\pi_{1}^{d}+\pi_{2}^{d}$. This reflects that the firms have asymmetric stakes: the defendant has a greater financial interest on the line, because its challenged conduct enhances total profits. We can now solve

\footnotetext{
${ }^{14} \mathrm{~A}$ procompetitive practice may a lead smaller rival to lose sales because it creates an efficiency (e.g. a cost reduction) that enables the dominant firm to offer consumers a much better deal than the rival can match. Thus, while we assume that firm 2's conduct (if continued) will ultimately lead firm 1 to go out of business, this result does not itself shed light on whether such conduct is pro- or anticompetitive.

${ }^{15}$ In fact, this assumption is necessary to explain why the firms do not simply strike a pre-litigation settlement in which firm 2 agrees to abstain from the challenged practice; such an agreement would be joint-profit enhancing if the assumption were violated. We discuss settlement in more detail below.

${ }^{16}$ When firm 1 wins, it avoids losing a duopoly profit of $\pi_{1}^{d}$ and also gets damages of $\delta$. When firm 2 wins, it avoids a profit reduction of $\pi^{m}-\pi_{2}^{d}$ and also avoids paying damages.
} 
for the equilibrium.

Proposition 2. The antitrust litigation game has a unique Nash equilibrium $\mathbf{x}^{*}=\mathbf{x}^{*}(w)$ with component strategies

$$
x_{i}^{*}=\frac{\alpha(1-\alpha) v_{i}^{2} v_{j}}{\left[\alpha v_{1}+(1-\alpha) v_{2}\right]^{2}} \text {. }
$$

Equivalently, these strategies can be written as

$$
x_{i}^{*}=v_{i} p^{*}\left(1-p^{*}\right)
$$

where $p^{*}=p^{*}(w)$ is the equilibrium probability that firm 1 prevails:

$$
p^{*}=\Phi\left(0 \mid \mathbf{x}^{*}, w\right)=\frac{\alpha v_{1}}{\alpha v_{1}+(1-\alpha) v_{2}} .
$$

Since $v_{2}>v_{1}$, it follows from $(7)$ that $x_{2}^{*}>x_{1}^{*}$. That is, firm 2 spends strictly more on litigation than does firm 1. In fact, the expenditure ratio $\left(x_{1}^{*} / x_{2}^{*}\right)$ is equal to the ratio of the firms' litigation stakes $\left(v_{1} / v_{2}\right)$. This leads to the following key result.

Proposition 3. As a result of the firms' asymmetric stakes $\left(v_{2}>v_{1}\right)$, the plaintiff's equilibrium winning probability is lower than the efficient level: $p^{*}<\alpha$ for any $w$.

Proof. By (8), we have $p^{*}<\alpha \Longleftrightarrow v_{2}>v_{1}$.

Thus, the firms' asymmetric stakes act to skew the equilibrium litigation odds in the defendant's favor, ${ }^{17}$ resulting in an inefficiently low win rate for plaintiffs. The equilibrium has some other interesting properties, too. It follows from (7) that if both firms' litigation stakes are scaled up or down by a common factor, then their expenditures will scale by the same factor, but the plaintiff's winning probability will remain unchanged.

Additionally, the factor $p^{*}\left(1-p^{*}\right)$ in (7) has a useful interpretation: if we think of the outcome of litigation as a binary random variable that equals unity with probability $p^{*}$ and zero otherwise, then $p^{*}\left(1-p^{*}\right)$ gives its variance. Therefore, $p^{*}\left(1-p^{*}\right)$ quantifies the

\footnotetext{
${ }^{17}$ For expediency, we will often use the term "litigation odds" as a shorthand for "the probability that the plaintiff will win in litigation."
} 
uncertainty in the outcome of litigation, which leads to some interesting implications. First, it follows from (7) that the firms make larger expenditures when the outcome of litigation is more uncertain. Second, the outcome is maximally uncertain (which occurs when $p^{*}=1 / 2$ ) when $\alpha v_{1}=(1-\alpha) v_{2}$, where the two sides represent the firms' stakes weighted by the strengths of their respective arguments.

More generally, it is easy to see that $p^{*}$ rises with the ratio $R=\frac{\alpha v_{1}}{(1-\alpha) v_{2}}$. In particular, we have $p^{*}=R /(R+1)$. This shows that the relative stakes $v_{1} / v_{2}$ are just as important as the relative merits $\alpha /(1-\alpha)$ in shaping the litigation odds. Thus, for example, even if the plaintiff has a strong case $(\alpha \gg 1 / 2)$, the outcome of litigation may still be quite uncertain if the disparity between the firms' litigation stakes is large. Finally, we note that the litigation game has the property that the firms' expenditures are neither strategic complements nor strategic substitutes; this is evident from the inverted-U shape of the best response functions, which are plotted in Figure 1 below. ${ }^{18}$

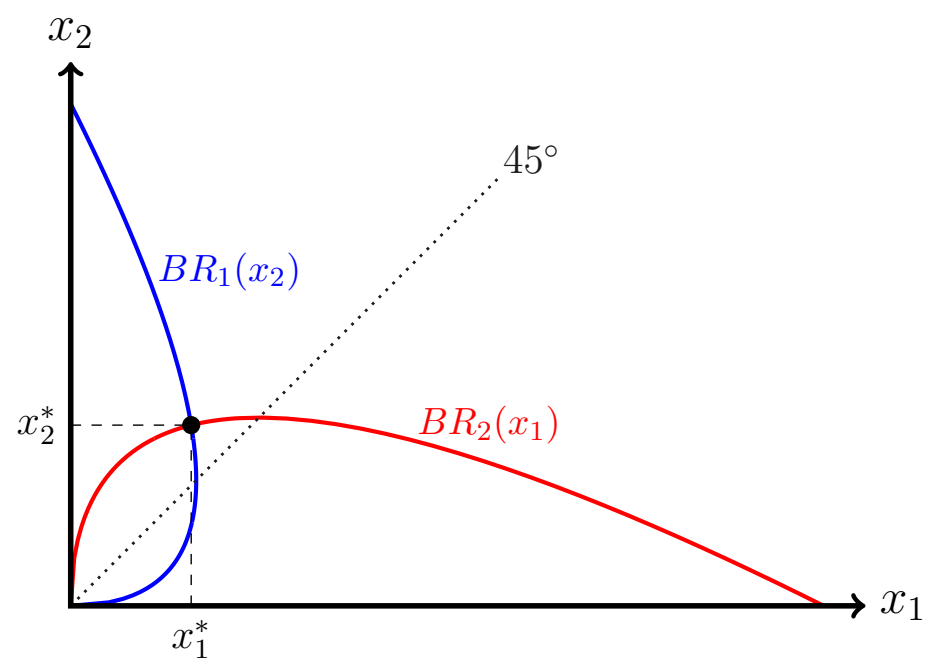

Figure 1: Best response functions and the equilibrium.

\subsection{Inadequacy of Enhanced Damages}

We now turn to the impact of damages on the equilibrium. One might expect that awarding sufficiently large damages could prevent the firms' asymmetric stakes from distorting the

${ }^{18}$ Firm $i$ 's best response function is

$$
B R_{i}\left(x_{j}\right)=\xi_{i} \sqrt{\alpha(1-\alpha) v_{i} x_{j}}-\frac{\xi_{i}}{\xi_{j}} x_{j},
$$

where $\xi_{1} \equiv 1 / \alpha$ and $\xi_{2} \equiv 1 /(1-\alpha)$. 
litigation odds. But in fact no finite damages award can eliminate the distortion. Rather, it would take infinite damages do accomplish this, as demonstrated in the proposition below.

Proposition 4. $p^{*} \rightarrow \alpha$ asymptotically as $\delta \rightarrow \infty$.

Proof. Using (8), this follows because $v_{2} / v_{1} \rightarrow 1$ asymptotically as $\delta \rightarrow \infty$.

Intuitively, increasing $\delta$ raises the litigation stakes for both firms, since it is just a transfer from one to the other. Therefore, while larger damages act to reduce the relative asymmetry, bringing $v_{2} / v_{1}$ closer to unity, they will never eliminate it. By contrast, if the stakes were symmetric $\left(v_{1}=v_{2}\right)$, then plaintiffs would achieve the optimal win rate $\left(p^{*}=\alpha\right)$ for any value of $\delta$.

However, enhanced damages may still help to deter potential defendants from engaging in anticompetitive conduct. Larger damages lead firm 2's expected litigation payoff to fall, which could potentially dissuade it from undertaking the disputed practice. But this point is not in tension with Proposition 4, which says that, conditional on litigation occurring, the litigation odds will be skewed in defendants' favor for any $\delta$.

\section{Settlement}

In this section, we first analyze the impact of ex post (post-judgment) settlements on the litigation equilibrium. When there are no legal constraints on settlements, nor any transaction costs to prevent effective contracting, we describe the ensuing settlements as "Coasean." We explain that the prospect of Coasean settlement will always act to prevent any skew in the litigation odds in equilibrium, even if the parties have asymmetric stakes. Therefore, in almost all areas of private litigation, the problem identified above will never arise in equilibrium, because most areas of law place no restrictions on ex post settlement.

However, we then explain that the problem cannot be avoided in antitrust. This is because antitrust law generally prohibits ex post settlements in which a losing defendant pays the plaintiff for the right to continue a practice that has just been declared anticompetitive. We conclude that antitrust stands apart from most other areas of private law - not because asymmetric stakes cannot arise in other contexts, but rather because they do not usually act to distort the litigation odds in equilibrium. 
We then discuss ex ante (pre-judgment) settlements that may seek to reach a compromise between the two possible outcomes of litigation. We explain that the problematic bias arising in the equilibrium litigation odds produces a similar problem in ex ante settlements, leading them to be less competitive than the optimal level.

\subsection{Ex Post Settlements}

It is well known in the law and economics literature that the prospect of ex post settlements can affect litigation incentives. In fact, when there are no legal constraints on such settlements, the prospect of Coasean settlement will lead the parties to make symmetric litigation expenditures in equilibrium, even if they have asymmetric stakes. We can establish this result using our litigation model and working by backward induction.

\subsubsection{Litigation in the Shadow of Coasean Settlement}

Consider a more generic version of the litigation game involving two private parties $i=$ 1,2 engaged in some (non-antitrust) legal dispute surrounding the conduct of party 2 (the defendant). We assume that the relevant area of law imposes no restrictions on ex post settlements. Consistent with the last section, let $v_{i}$ denote party $i$ 's litigation stakes (its incremental value from winning rather than losing), which includes some damages award $\delta \geq 0$. As before, we suppose that $v_{2}>v_{1}$, so that the parties have asymmetric stakes due to the disparate payoff effects of an injunction. ${ }^{19}$ It follows that, if the plaintiff wins, the parties can jointly-benefit from contracting around the injunction ex post. ${ }^{20}$ At the margin, this raises the parties' joint-payoffs by $v_{2}-v_{1}>0$. To ensure that both of them are left better off, party 2 makes a payment to party $1 .^{21}$ The payment, denoted $\tau$, takes the form

$$
\tau \equiv v_{1}-\delta+\beta\left(v_{2}-v_{1}\right)
$$

\footnotetext{
${ }^{19}$ It is easy to see that a pure damages action (one that does not seek an injunction) must involve symmetric stakes, namely $v_{1}=v_{2}=\delta$. Hence, if the litigants have asymmetric stakes, the asymmetry must stem from the effects of an injunction.

${ }^{20}$ For example, in a nuisance claim against a noisy factory, a successful plaintiff may win an injunction ordering the defendant to halt its noisy operations. But the parties may then strike an ex post agreement in which the plaintiff sells the defendant a license to resume its operations.

${ }^{21}$ In the alternative case $v_{1}>v_{2}$, the parties would instead contract around a win for the defendant, so that the payment would run from party 1 to party 2 .
} 
where $\beta \in[0,1]$ denotes the bargaining power of party 1 , which specifies its share of the gains from trade $\left(v_{2}-v_{1}\right)$. The term $-\delta$ reflects that the settlement payment will not duplicate the damages award, which the defendant pays separately -immediately after the court enters a judgment for the plaintiff and prior to the ex post settlement. Thus, when the plaintiff wins, the overall amount it receives from the defendant is $\tau+\delta=v_{1}+\beta\left(v_{2}-v_{1}\right)$.

By backward induction, we know that the court's judgment will not influence whether or not the defendant's conduct will persist ex post: it definitely will. ${ }^{22}$ Rather, the court's decision merely determines whether the defendant will have to pay for this privilege. We can thus write the parties' payoff functions as

$$
u_{1}=k_{1}+p(\tau+\delta)-x_{1}, \quad u_{2}=k_{2}-p(\tau+\delta)-x_{2},
$$

where $k_{1}$ and $k_{2}$ give the parties' payoffs (excluding litigation costs) when the plaintiff loses. (In the antitrust case we had $k_{1}=0$ and $k_{2}=\pi^{m}$.) Given these payoff functions, the parties will behave exactly as if they had symmetric stakes. The result is that the plaintiff's success probability will not be skewed away from $\alpha$ in equilibrium.

Proposition 5. Consider the litigation game where there are no restrictions on Coasean settlements. There is a unique equilibrium with strategies

$$
x_{1}^{*}=x_{2}^{*}=(\tau+\delta) \times \alpha(1-\alpha)
$$

and the plaintiff wins with probability $p^{*}=\alpha$.

Intuitively, the settlement payment $\tau$ acts just like a damages award: it makes symmetric contributions to the parties' litigation stakes. Thus, when the litigants can always bargain around the court's judgment, they will behave as if the stakes are symmetric, even if $v_{2}>v_{1}$. Put differently, even if an injunction (if enforced) would have disparate effects on the litigants' payoffs, this will not be reflected in equilibrium behavior, for the parties anticipate that the injunction will be lifted (via contract) if the plaintiff wins.

\footnotetext{
${ }^{22}$ This is simply an application of the Coase theorem. However, even if transaction costs are sufficiently low to permit private contracting, the theorem does not obtain if there are legal constraints on ex post settlements. In this case the court's judgment may influence the final allocation of rights even if transaction costs are negligible. This was observed in the context of horizontal patent settlements by Hovenkamp (2018).
} 


\subsubsection{Antitrust Restrictions on Ex Post Settlements}

Antitrust litigants would also be eager to strike a Coasean settlement if the plaintiff wins. They would mutually-benefit from a settlement that maintains (and shares) the monopoly profit, since this exceeds total duopoly profits. ${ }^{23}$ However, antitrust prohibits such ex post settlements. If the court enters a judgment for the plaintiff, declaring the defendant's conduct anticompetitive and issuing an injunction, then the firms cannot lawfully contract around this by agreeing that firm 2 will compensate firm 1 in exchange for continuing its exclusionary practice. The plaintiff does not have the authority to "license" the defendant's anticompetitive behavior in exchange for cash.

This makes sense, because a settlement that effectuates anticompetitive conduct would have third-party effects: it would injure downstream consumers. An injury to consumer welfare does not cease to be an antitrust violation just because firm 1 consents to let it happen. On the contrary, such a settlement would amount to a collusive agreement in which a dominant firm pays its rival to exit. Thus, if such ex post settlements were not proscribed by antitrust, they would provide a backdoor mechanism for striking anticompetitive horizontal agreements. It follows that the skew in the litigation odds identified in Proposition 3 will persist in equilibrium due to this relatively unusual constraint on the legality of ex post settlements. $^{24}$

In principle, the parties may attempt to evade this result by reaching a settlement during the pendency of an appeal filed by the defendant; they might then petition the court to vacate the injunction in light of their settlement, which is up to the discretion of the judge. However, if the appellate court has not yet ruled on the defendant's appeal - and therefore has not found that district court erred in finding a violation - then there is no sound basis for vacating the injunction. On the contrary, it would be a perverse mistake for a court to condone a settlement authorizing conduct that the court itself found to be anticompetitive.

\footnotetext{
${ }^{23}$ Recall that this is why we have $v_{2}>v_{1}$.

${ }^{24}$ Similar restrictions on ex post settlements arise in some IP contexts. For example, in a patent dispute, if the court deems the patent invalid, the parties cannot circumvent this with a contract in which the patentee pays the other party to abstain from using the relevant invention (Hovenkamp, 2018). Once the patent is invalidated, its owner has no more lawful basis for excluding or restraining anyone's use of the invention. The illegality of such a settlement is most obvious where the patentee is a monopolist and the other party is a potential entrant, in which case the settlement amounts to naked market division.
} 


\subsection{Ex Ante Settlements}

The preceding discussion raises the question of whether the firms can evade the legal constraints on ex post settlements by settling ex ante, before the judge issues a final judgment. In principle, this could be used to generate a monopoly for the dominant firm, while also providing a payment to the plaintiff that ensures the deal is mutually-beneficial. ${ }^{25}$ In this case, the ex ante settlement would look very much like the kind of ex post settlement that antitrust forbids. The only difference is that the payment would depend in part on the plaintiff's winning probability $\left(p^{*}\right)$, as this determines what size the payment must be in order to satisfy both firms; the larger is $p^{*}$, the larger the payment will be. Because this kind of settlement always preserves monopoly, the only impact of asymmetric stakes is to make the payment somewhat smaller.

Of course, this kind of settlement likely would (and certainly should) be condemned in most instances. Such an arrangement would resemble the "pay-for-delay" patent settlements considered in the Supreme Court's recent Actavis decision. ${ }^{26}$ In a pay-for-delay settlement, a monopolist (whose monopoly hinges on a patent) pays off a prospective entrant who is challenging the patent's validity in court. The deal gives the challenger a large "reverse payment" in exchange for dropping its challenge and staying out of the market until the patent is about to expire. The Court held that this kind of settlement is typically illegal because, in effect, it fully eliminates competition (over the remaining patent term) with certainty, whereas a final judgment on the patent's validity had a significant probability of inviting new competition. ${ }^{27}$ Similarly, an antitrust suit has the possibility of engendering greater competition by enjoining an anticompetitive practice, and an ex ante settlement could be used to extinguish that possibility. The logic of Actavis would then suggest that such settlements are typically unlawful.

An alternative possibility is that the settlement could reduce, but not eliminate, the exclusionary threat posed by the defendant's conduct. That is, the defendant agrees to "tone down" its disputed conduct, but does not suspend it completely. In this case, the settlement's impact on competition falls somewhere between the two possible outcomes of litigation. Importantly, this settlement format must not permit firm 2 to make a payment to firm 1, or

\footnotetext{
${ }^{25}$ If permitted, this kind of deal would always be Pareto efficient for the firms, since total profits are maximized under monopoly and a payment term lets the firms divvy up total profits however they like.

${ }^{26}$ FTC v. Actavis, Inc., 570 U.S. 136 (2013). See also, e.g., Shapiro (2003); Hemphill (2006); Hovenkamp (2019).

${ }^{27}$ That a final judgment has "significant probability" of invalidating the patent can be inferred when the payment is sufficiently large (e.g. larger than the cost of litigation). See, e.g., Edlin et al. (2015).
} 
else the firms will always mutually-agree to let firm 2 continue its exclusionary conduct in full, resulting in the same kind of monopoly-for-cash settlement considered above. ${ }^{28}$

Consider an illustrative example. The defendant is engaging in exclusive dealing that prevents $N$ large suppliers of an essential input from selling to the plaintiff-rival. If the plaintiff prevails in court, all $N$ of these deals will be enjoined. In ex ante settlement negotiations, the firms bargain over a reduction $S$ in the number of exclusivity contracts, resulting in $N-S$ agreements remaining in force. For simplicity, we will assume that the firms' profits under such a settlement are linear in $S .^{29}$ The absence of a payment ensures that the maximallyanticompetitive settlement outcome $(S=0)$ is generally not acceptable to the plaintiff, as it anticipates getting a more favorable result from litigation; similarly, the defendant will generally not agree to the most procompetitive outcome $(S=N)$. Instead, a mutuallyagreeable settlement will have to produce an outcome that lines up with the expected result of litigation. ${ }^{30}$ Specifically, letting $p^{*}$ denote the plaintiff's winning probability, the firms will agree to eliminate about $S=p^{*} N$ of the exclusive deals, which coincides with the expected result of litigation. ${ }^{31}$

This settlement is clearly preferable to the sort of monopoly-for-cash agreement considered earlier, and there are good reasons for thinking such settlements would very likely be lawful. ${ }^{32}$ However, our main point is just to point out that such settlements will be systematically under-competitive as a result of asymmetric stakes. Because the asymmetry distorts the litigation odds, it will similarly distort the firms' expectations about litigation and, by extension, the competitiveness of their settlement. Thus, the problem is not that the settlement outcome will fail to comport with the expected result of litigation, but rather that the latter benchmark has been distorted by a downward bias in the plaintiff's winning probability. For example, suppose that $\alpha=1 / 2$, whereas $p^{*}=1 / 4$. Then ideally the settlement would

\footnotetext{
${ }^{28} \mathrm{~A}$ more permissive rule would merely proscribe payments in excess of the likely cost of litigation. This cap on the payment has often been promoted in the pay-for-delay context (see Edlin et al., 2015), and the Actavis majority acknowledged it as a reasonable benchmark.

${ }^{29}$ For example, this is so if settlement profits are $\frac{S}{N} \pi_{1}^{d}$ for the plaintiff and $\frac{S}{N} \pi_{2}^{d}+\left(1-\frac{S}{N}\right) \pi^{m}$ for the defendant.

${ }^{30}$ The role of the payment was to avoid this incentive compatibility constraint by letting the defendant compensate the plaintiff in a way that does not translate into greater competition.

${ }^{31}$ For simplicity, we are ignoring the likelihood that profits are nonlinear in the number of exclusive deals.

${ }^{32}$ First, this view is consistent with the policy underpinning the Supreme Court's Actavis decision-namely, that we would like horizontal settlements to generate roughly the same amount of competition as the expected result of litigation - a normative standard first proposed by Shapiro (2003). (See also Hovenkamp and Lemus (2019) for discussion of how this standard can be administered by analyzing the structure of the settlement agreement.) Second, it is generally not feasible to demand that a horizontal settlement be more competitive than the expected result of litigation: such a result would engender lower total profits than the firms expect to obtain through litigation, in which case it could not be mutually beneficial. Thus, a more stringent standard would have the perverse consequence of making settlement impossible.
} 
involve the defendant reducing its exclusivity commitments by half $(S=\alpha N)$, because that result is commensurate with the expected result of unbiased litigation. But, because the plaintiff's actual (biased) winning probability is $p^{*}=1 / 4$, the defendant will instead reduce its exclusivity commitments by just a quarter $\left(S=p^{*} N\right)$.

\section{Presumptions}

Our analysis in Section 2 showed asymmetric stakes lead the plaintiff's equilibrium winning probability $p^{*}$ to be strictly lower than the optimal level, $\alpha$. Further, we showed in Section 2.3 that enhanced damages cannot prevent this systematic distortion. However, in this section we show that courts could address the problem by modifying the plaintiff's evidentiary burden. Specifically, we consider how courts might adjust the plaintiff's evidentiary burden by using a presumption to augment their decision-making.

A presumption leads courts to maintain an initial predisposition toward one outcome or the other, although this can be rebutted if evidence favoring the opposite result is sufficiently compelling. This makes a plaintiff's evidentiary burden either "lighter" or "heavier," depending on which side the presumption favors. We implement this in our model by supposing that courts' decision-making process is modified in the following way: rather than entering judgment for the plaintiff whenever it observes a signal value $y<0$, as assumed previously, we now assume that the plaintiff wins whenever $y<\eta$, where $\eta$ is some real number. We

interpret a nonzero value of $\eta$ as a presumption. A presumption with $\eta>0$ (resp. $\eta<0$ ) makes it systematically easier (resp. harder) for plaintiffs to win, all else being the same, and the magnitude of this effect is governed by the absolute value $|\eta|$.

We next solve the litigation game for the case of an arbitrary presumption $\eta$ and explain how the value of $\eta$ could be set to counter the systematic distortion created by asymmetric stakes. We also consider the possibility that there are also independent reasons - relating to the nature of the defendant's conduct and its propensity to injure consumers - for using a presumption to modify the plaintiff's evidentiary burden. 


\subsection{Litigation Equilibrium with a Presumption}

Let us fix a presumption $\eta \in \mathbb{R}$, so that the plaintiff wins in litigation if and only if the court observes a signal satisfying $y<\eta$. We define $\alpha_{\eta}=\alpha_{\eta}(w)$ by

$$
\alpha_{\eta}=F(\eta \mid w)
$$

This is exactly analogous to the definition of $\alpha$ in (2), which would now be denoted by $\alpha_{0}$, reflecting that it corresponds to the absence of a presumption $(\eta=0)$. Then, conditional on $\mathbf{x}$ and $w$, the probability that firm 1 will prevail in litigation is given by $p_{\eta}=p_{\eta}(\mathbf{x}, w)$, defined by

$$
p_{\eta}=\Phi(\eta \mid \mathbf{x}, w)=\frac{\alpha_{\eta} x_{1}}{\alpha_{\eta} x_{1}+\left(1-\alpha_{\eta}\right) x_{2}}
$$

Adding a presumption affects the firms' payoffs only by influencing the litigation odds. Thus, payoff functions will take the same functional form as before, but with $p$ now replaced by the more general term $p_{\eta}$. It is easy to compute the equilibrium in the litigation game with a presumption.

Proposition 6. In the antitrust litigation game with a presumption $\eta$, there is a unique Nash equilibrium $\mathbf{x}_{\eta}^{*}=\mathbf{x}_{\eta}^{*}(w)$ with component strategies

$$
x_{i, \eta}^{*}=\frac{\alpha_{\eta}\left(1-\alpha_{\eta}\right) v_{i}^{2} v_{j}}{\left[\alpha_{\eta} v_{1}+\left(1-\alpha_{\eta}\right) v_{2}\right]^{2}}=v_{i} p_{\eta}^{*}\left[1-p_{\eta}^{*}\right],
$$

where $p_{\eta}^{*}=p_{\eta}^{*}(w)$ is the equilibrium probability that the plaintiff wins:

$$
p_{\eta}^{*}=\Phi\left(\eta \mid \mathbf{x}_{\eta}^{*}, w\right)=\frac{\alpha_{\eta} v_{1}}{\alpha_{\eta} v_{1}+\left(1-\alpha_{\eta}\right) v_{2}} .
$$

Proof. The result follows from the proof of Proposition 2, but with $\alpha$ and $p$ replaced by $\alpha_{\eta}$ and $p_{\eta}$, respectively.

This is just a modest generalization of Proposition 2, which can now be viewed as capturing the special case of $\eta=0$. It is easy to verify that $\alpha_{\eta}$ is strictly increasing in $\eta$, and therefore $p_{\eta}^{*}$ is likewise increasing in $\eta$. Accordingly, if $\eta>0$, then we have $\alpha_{\eta}>\alpha_{0}$ and therefore $p_{\eta}^{*}>p_{0}^{*}$, so that the presumption improves the plaintiff's litigation odds; the converse occurs when $\eta<0$.

By inspection of (13), a presumption will not prevent the firms from making asymmetric 
expenditures in equilibrium; that is, we still have $x_{2, \eta}^{*}>x_{1, \eta}^{*}$ for any $\eta$. But this does not imply that a presumption cannot eliminate the distortion in the litigation odds, because the presumption still affects the plaintiff's equilibrium winning probability. The value of $\eta$ can therefore be adjusted to undo the distortion created by asymmetric stakes. For example, we could choose the value $\eta=\widehat{\eta}$ defined by $p_{\widehat{\eta}}^{*}=\alpha_{0}$. Using (14), $\widehat{\eta}$ is determined by

$$
\alpha_{\widehat{\eta}}=\frac{\alpha_{0} v_{2}}{\alpha_{0} v_{2}+\left(1-\alpha_{0}\right) v_{1}}
$$

However, this is not very useful, because $\alpha_{0}$ is a function of $w$, which the court does not observe. Instead, what we need is a notion of an optimal presumption that does not rely on information about the true welfare effect arising in any given case. To accomplish this, we will suppose that a legal authority (e.g. Congress or the Supreme Court) chooses an optimal presumption based on probabilistic information about the welfare effects generated by the defendant's conduct, as captured by a Bayesian prior. This leads to a presumption that accounts not only for asymmetric stakes, but also any underlying predisposition of the challenged practice toward pro- or anticompetitive effects.

\subsection{Optimizing Presumptions for Specific Practices}

In antitrust, presumptions are typically employed when there is a belief among courts that a given practice is, in general, usually anticompetitive or usually procompetitive, even though it may be difficult to estimate its welfare effects directly in any given case. ${ }^{33}$ Such beliefs can be represented by a Bayesian prior. To make this explicit, let $\rho(w)$ be a prior probability density over the welfare effects generated by a particular type of practice (e.g. exclusive dealing or vertical merger). ${ }^{34}$ Hence, before any case-specific facts are accounted for, the prior probability that the practice is anticompetitive is given by $\mathrm{P}_{\rho}\{w<0\}=\int_{-\infty}^{0} \rho(w) d w$. We make the following assumption on the prior $\rho$.

Assumption 3. The prior density $\rho(w)$ is symmetric with support $\mathbb{R}$.

We let $\mu$ denote the mean welfare effect under $\rho$, which is also the median in light of the above assumption. The sign of $\mu$ captures whether the relevant practice is regarded as usually anticompetitive $(\mu<0)$, usually procompetitive $(\mu>0)$, or neutral on average $(\mu=0)$. In order to fix an optimal presumption, we must ask about the posterior probability that a

\footnotetext{
${ }^{33}$ For a discussion of antitrust presumptions, see Gavil and Salop (2020).

${ }^{34}$ As this suggests, our analysis is now conditional on a particular type of restrictive practice.
} 
practice is anticompetitive, conditional on the signal observed by the court and the firms' litigation expenditures. Letting $\phi \equiv \partial \Phi / \partial y$ denote the signal density, Bayesian-updating gives the following posterior probability of anticompetitive harm:

$$
\mathrm{P}_{\rho}\{w<0 \mid y, \mathbf{x}\}=\frac{\mathrm{P}_{\rho}\{w<0, y \mid \mathbf{x}\}}{\mathrm{P}_{\rho}\{y \mid \mathbf{x}\}}=\frac{\int_{-\infty}^{0} \rho(w) \phi(y \mid \mathbf{x}, w) d w}{\int_{-\infty}^{\infty} \rho(w) \phi(y \mid \mathbf{x}, w) d w} .
$$

We assume that the optimal presumption is that which would perfectly effectuate the preponderance-of-evidence standard. This means that the defendant's conduct should be condemned if and only if the observed signal value $y$ (viewed in light of the prior) suggests that the defendant's conduct is more likely to be anticompetitive than procompetitive-i.e. $w$ is more likely to be negative than nonnegative. It follows that the optimal value of $\eta$ is that which ensures the above posterior probability is equal to $1 / 2$ when $y=\eta$.

As (16) indicates, posterior probabilities depend on the firms' expenditures. But recall that the court does not observe $\mathbf{x}$ in any given case. Thus, to avoid an ambiguity over $\mathbf{x}$, we must specify a decision rule about how firms choose their expenditures; we can then compute posterior probabilities under the assumption that the firms always adhere to this decision rule. There are two such specifications worth considering - namely, symmetric expenditures ${ }^{35}$ and equilibrium expenditures. These possibilities give rise to alternative conceptions of the optimal presumption, which are described below:

Pure Conduct-Based Presumption: The optimal presumption, denoted $\widetilde{\eta}$, conditional on the assumption that firms make symmetric expenditures $\left(x_{1}=\right.$ $x_{2}$ ). The value of $\widetilde{\eta}$ is pinned down by

$$
\mathrm{P}_{\rho}\left\{w<0 \mid y=\widetilde{\eta}, x_{1}=x_{2}\right\}=\frac{1}{2} .
$$

First-Best Presumption: The optimal presumption, denoted $\eta^{*}$, conditional on the assumption that firms make equilibrium expenditures $\left(\mathbf{x}=\mathbf{x}_{\eta}^{*}\right)$. The value of $\eta^{*}$ is pinned down by

$$
\mathrm{P}_{\rho}\left\{w<0 \mid y=\eta^{*}, \mathbf{x}=\mathbf{x}_{\eta^{*}}^{*}\right\}=\frac{1}{2}
$$

Pure Stakes-Based Presumption: The special case $\eta_{0}^{*}$ of the first-best presumption when the prior has $\mu=0$.

\footnotetext{
${ }^{35}$ The specific value of $x_{1}=x_{2}$ is irrelevant, because $\phi(y \mid \mathbf{x}, w)$ reduces to $f(y \mid w)$ whenever expenditures are symmetric (Assumptions 1-2), in which case $\mathbf{x}$ drops out of the posterior in (16).
} 
As the name suggests, the pure conduct-based presumption $\widetilde{\eta}$ focuses exclusively on the nature of the defendant's conduct - its propensity to elicit anticompetitive effects - as captured by the prior $\rho$. This presumption thus ignores the problem of asymmetric stakes by assuming $x_{1}=x_{2}$. By contrast, the first-best presumption $\eta^{*}$ accounts for both the nature of the defendant's conduct and the distortion created by asymmetric stakes. ${ }^{36}$ Finally, the pure stakes-based presumption is just the first-best presumption in the case where the prior takes a neutral position on the practice in question $(\mu=0)$, in which case the only need for a presumption is to correct the distortion created by asymmetric stakes. We now present this Section's main result.

Proposition 7. For any prior $\rho(w)$ satisfying Assumption 3, we have

(i) $\operatorname{sign}\{\widetilde{\eta}\}=-\operatorname{sign}\{\mu\} \cdot 37$

(ii) $\eta^{*}>\widetilde{\eta}$

(iii) $\eta_{0}^{*}$ is pinned down by

$$
F\left(\eta_{0}^{*} \mid 0\right)=\frac{v_{2}}{v_{1}+v_{2}}
$$

Unsurprisingly, part $(i)$ indicates that if the relevant conduct is predisposed toward anticompetitive effects $(\mu<0)$, then the pure conduct-based presumption must counterbalance this by tilting the scales in plaintiffs' favor $(\widetilde{\eta}>0)$, and vice versa; otherwise we have $\widetilde{\eta}=\mu=0$. However, part $(i i)$ states the first-best presumption will always be strictly more favorable to plaintiffs than the conduct-based one, regardless of what value the latter takes. This reflects the fact that asymmetric stakes always skew the litigation odds in defendants' favor. Therefore, countering this distortion always requires increasing the presumption.

The pure stakes-based presumption $\eta_{0}^{*}$ is optimal when courts maintain a neutral prior over the practice in question $(\mu=0)$. We can use equation (19) to see how $\eta_{0}^{*}$ addresses the problem of asymmetric stakes. Consider the case where the true welfare effect is exactly $w=$ 0 . Then, absent a presumption, the strength of the plaintiff's case would be $\alpha_{0}=F(0 \mid 0)=$ $1 / 2$, whereas the plaintiff's equilibrium winning probability would be $p_{0}^{*}=v_{1} /\left(v_{1}+v_{2}\right)<1 / 2$; this is the usual distortion created by asymmetric stakes. Now consider what happens when we implement the presumption $\eta_{0}^{*}$ defined in (19), while continuing to assume $w=0$. The presumption reduces the plaintiff's evidentiary burden, so that the strength of its claim

\footnotetext{
${ }^{36}$ Note that, as indicated in (18), the first-best presumption $\eta^{*}$ must account for the fact that the firms' equilibrium expenditures themselves depend on the choice of presumption.

${ }^{37}$ In the special case $\rho(\cdot)=f(\cdot \mid \mu)$, we have $\widetilde{\eta}=-\mu$ (see the proof of part $\left.(\mathrm{i})\right)$.
} 
increases to

$$
\alpha_{\eta_{0}^{*}}=F\left(\eta_{0}^{*} \mid 0\right)=\frac{v_{2}}{v_{1}+v_{2}}>\frac{1}{2}
$$

which induces the desired winning probability in equilibrium:

$$
p_{\eta_{0}^{*}}^{*}=\frac{\alpha_{\eta_{0}^{*}} v_{1}}{\alpha_{\eta_{0}^{*} v_{1}}+\left(1-\alpha_{\eta_{0}^{*}}\right) v_{2}}=\frac{\frac{v_{1} v_{2}}{v_{1}+v_{2}}}{\frac{v_{1} v_{2}}{v_{1}+v_{2}}+\frac{v_{1} v_{2}}{v_{1}+v_{2}}}=\frac{1}{2}=\alpha_{0} .
$$

However, recalling that $p_{\eta}^{*}$ and $\alpha_{\eta}$ are functions of $w$, we note that the presumption does not achieve $p_{\eta_{0}^{*}}^{*}(w)=\alpha_{0}(w)$ for all values of $w$. Instead, by (globally) shifting the equilibrium probability upward from $p_{0}^{*}(w)$ to $p_{\eta_{0}^{*}}^{*}(w)$, the presumption ensures only that the latter is everywhere closer to $\alpha_{0}(w) .{ }^{38}$ It is not possible to do better than this: to achieve $p_{\eta_{0}^{*}}^{*}(w)=$ $\alpha_{0}(w)$ globally would require making the presumption a function $w$, but that would be inconsistent with the courts' inability to observe $w{ }^{39}$ In light of this constraint, we have employed a weaker notion of optimality - namely, that the optimal presumption is that which perfectly effectuates the preponderance-of-evidence standard, as discussed above.

\section{Extensions}

\subsection{Consumer Class Actions}

Our analysis has shown that when the plaintiff is a rival of the dominant firm, the firms have asymmetric stakes that distort the litigation odds in the defendant's favor. But an excluded rival does not internalize the consumer welfare effects of the defendant's conduct. This raises the question of whether the problem of asymmetric stakes would vanish (or even reverse directions) if the plaintiff instead were a class composed of all injured consumers. In that case, one might think that, if the defendant's conduct reduces total welfare, then the asymmetric stakes would be reversed. However, that is not necessarily correct. An injunction's incremental benefit to consumers may or may not exceed the incremental reduction in the defendant's profits. The reason is that the defendant internalizes not only the injunction's effect in reducing in total profits, but also its effect in reallocating some profits to the

\footnotetext{
${ }^{38}$ One can verify that $p_{\eta_{0}^{*}}^{*}(w)$ crosses $\alpha_{0}(w)$ from above at $w=0$ (and nowhere else). By contrast, $p_{0}^{*}(w)$ lies everywhere below both $\alpha_{0}(w)$ and $p_{\eta_{0}^{*}}^{*}(w)$.

${ }^{39}$ See equation (15) and the discussion that follows.
} 
excluded rival. ${ }^{40}$

However, even if an injunction would benefit consumers by more than it reduces the defendant's profits, the defendant is likely to internalize larger litigation stakes than the consumer class for several reasons. First, there are the usual practical difficulties in achieving efficient collective action by a large group of injured parties due to various externality, free-riding, and information problems associated with class actions generally. ${ }^{41}$ Second, antitrust standing rules limit potential recovery to those consumers who actually bought the relevant product at a supra-competitive price; consumers who were deterred from buying the product (whose injuries are thus reflected in deadweight loss) are not eligible to join the class. Thus, the class will only partially internalize the social benefits of an injunction.

Finally, and most importantly, it is not the consumers but rather their attorneys who make the operative choice of litigation effort in this context. Class action attorneys do not charge hourly fees, but rather work on a contingency basis, earning payment only upon winning the case or securing a monetary settlement; their payment is then given as a percentage of the total monetary award. The consumers themselves do not make out-of-pocket expenses on litigation. Rather, the attorneys choose how much costly effort to invest (including costs of retaining experts, consultants, etc.) in consideration of the likelihood of winning and the expected size of the payment they would receive upon success. But as a result of their payoff structure, they do not internalize the consumer value from an injunction, and they internalize only a portion of any awarded damages. By contrast, the defendant internalizes both the full damages award and the negative profit effects of an injunction. As a result, the defendant's litigation stakes will be substantially greater than those internalized by the operative decision-maker on the consumer side. ${ }^{42}$

\footnotetext{
${ }^{40}$ An injunction reduces producer surplus by $\Delta P S \equiv \pi^{m}-\left(\pi_{1}^{d}+\pi_{2}^{d}\right)$, which must satisfy $\Delta P S<|w|$ if the injunction would increase total welfare. However, the defendant internalizes a profit change of $\Delta \pi_{2} \equiv$ $\pi^{m}-\pi_{2}^{d}>\Delta P S$. Therefore, it is possible that $\Delta \pi_{2}>|w|$ even if the injunction would increase total surplus.

${ }^{41}$ See, e.g., Spier (2007); Issacharoff (1996); Morawetz (1993).

${ }^{42}$ One might wonder whether the asymmetric stakes might be reversed in a consolidated action with plaintiffs comprising both a rival firm and a consumer class might exceed the stakes for the defendant. This would not seem to be possible: the rival internalizes only a portion of a social value of an injunction - a lesser amount than the profit losses internalized by the defendant-whereas the class attorneys internalize only a portion of the monetary award given to its consumer clients. Hence the defendant continues to internalize a larger financial stake. In any case, consumer class actions usually follow successful suits by other plaintiffs; it is not typical for a consumer action to be consolidated with an action brought by a rival.
} 


\section{$5.2 \quad$ Fee Shifting}

By statute, a successful private antitrust plaintiff may recover "a reasonable attorney fee" from the defendant. ${ }^{43}$ There is no analogous rule for successful defendants, and hence private antitrust litigation involves "one-way fee shifting" However, for several reasons, this is very different from a rule in which a losing defendant must pay the plaintiff's subjectively-chosen litigation expenditure, as given by $x_{1}$ in our model. ${ }^{44}$

First, the rule requires the defendant to pay an amount the court deems "reasonable" for the case in question, as opposed to the actual amount paid by the plaintiff to its attorneys. ${ }^{45}$ Courts thus rely on one of several objective approaches for determining a "reasonable" fee, which can be as coarse as simply setting the fee equal to a percentage of damages. Consequently, in practice the plaintiff's fee award "can be entirely independent of what the plaintiff has agreed to pay its lawyer." 46 Further, because the approaches used to calculate fees are so imprecise, fee awards are infamously random and inconsistent. ${ }^{47}$ Finally, fee shifting does not cover several of the most significant aspects of the plaintiff's litigation expenditure: the costs of hiring testifying experts, non-testifying experts, and consultants. ${ }^{48}$

For these reasons, a sensible way to capture fee shifting in our model would be to introduce some fixed monetary award (i.e. one that is independent of $x_{1}$ ) that reflects the court's assessment of what fees would be "reasonable" for the case in question; the plaintiff would then recover this additional amount in the event that it wins. But then the award would act exactly like an increase in the damages parameter $\delta$. Thus, following our discussion of damages in Section 2.3, we conclude that antitrust's one-way fee shifting acts to reduce the distortion created by asymmetric stakes, but does not eliminate it.

\footnotetext{
${ }^{43}$ Clayton Act $\S 4$ (15 U.S.C. $\left.\S 15(a)\right)$.

${ }^{44}$ If one modifies our model so that the defendant must pay $x_{1}$ to the plaintiff upon losing, then the plaintiff's best-response behavior becomes pathological, prescribing an infinite expenditure in some situations. But this can be avoided by assuming that each firm's probability of losing can never fall below some small lower bound $\varepsilon>0$ (e.g. the risk of losing on a technicality).

${ }^{45}$ This is intended to avoid a moral hazard problem: plaintiffs might rack up excessive bills if they could expect full reimbursement of whatever amount they choose to spend.

${ }^{46} 2$ Phillip E. Areeda \& Herbert Hovenkamp, Antitrust Law 9330 e, at pp. 48-49 (4th ed., 2014).

${ }^{47}$ E.g., Berger (1977) notes that fee awards amount to a "roll of the dice" and that "[t]he only truly consistent thread...is their almost complete inconsistency."

${ }^{48}$ See, e.g., Concord Boat Corp. v. Brunswick Corp., 34 F. Supp. 2d 1125, 1131 (E.D. Ark. 1998) (noting that fees paid to experts and consultants "are not recoverable" by the successful antitrust plaintiff.) This follows a Supreme Court decision that fee shifting statutes exclude expert/consultant fees unless such fees are explicitly provided for. Crawford Fitting Co. v. J.T. Gibbons, Inc., 482 U.S. 437, 439 (1987).
} 


\section{Conclusion}

When an antitrust defendant is a dominant firm accused of exclusionary conduct by a smaller rival or entrant, the defendant generally has much higher stakes than does the plaintiff. These asymmetric stakes and their effect on litigation effort likely are very important for antitrust litigation involving exclusionary conduct. The loss of monopoly power can reduce the net present value of the dominant firm's profits by billions of dollars, while an injunction generally would provide substantially lower profits to the plaintiff, and damages are unlikely to affect the relative stakes by that much. For example, while it is hard to know what fraction of Windows' profits were at stake in the Microsoft litigation, Microsoft's stock price fell from about $\$ 52$ on Friday March 31 to about $\$ 42.5$ on April 4, the day after the antitrust opinion was released - a reduction of about $\$ 80$ billion. ${ }^{49}$ By contrast, the stakes for the private plaintiffs such as RedHat, VA Linux, Sun and Novell were surely much smaller.

This paper explores the impact of this systematic imbalance on litigation with endogenous effort. Our model shows that asymmetric stakes always lead the plaintiff's winning probability to be distorted below the efficient level. The problem is not avoided by settling before judgment, for we have also shown that asymmetric stakes lead ex ante settlements to generate too little competition. While asymmetric stakes can arise in all areas of private law, we explain that they do not usually cause this kind of distortion in equilibrium; the distortion arises in antitrust only because it constrains the legality of certain ex post settlements that would be antithetical to antitrust policy. This constraint affects decision-making at the litigation stage, leading the asymmetric stakes to distort the equilibrium.

We show that enhanced damages can help to reduce the problem, but can never eliminate it. However, courts could do better by reducing the plaintiff's evidentiary burden to offset the distortion. This is a timely issue in light of the current concerns that antitrust law has been an insufficient constraint on the conduct of dominant firms, ${ }^{50}$ which has led to legislative proposals as well as academic recommendations for judicial adjustments to legal standards. ${ }^{51}$

\footnotetext{
${ }^{49}$ This reduction could be an underestimate because the judge's earlier announced factual findings signaled a substantial likelihood that there would be some liability, and there was a probability of a successful future appeal. Microsoft paid out about $\$ 5$ billion in damages in private cases and about $\$ 4$ billion in fines to the European Commission. See Gavil and First (2014) at p. 274.

${ }^{50}$ See, e.g., the Stigler Center's recent report on potentially anticompetitive practices by dominant digital platforms, available at https://research.chicagobooth.edu/stigler/media/news/committee-on-digitalplatforms-final-report.

${ }^{51}$ See, e.g., Gavil and Salop (2020); Federico et al. (2020).
} 


\section{References}

Ian Ayres and Barry Nalebuff. The rule of probabilities: a practical approach for applying bayes' rule to the analysis of dna evidence. Stan. L. Rev., 67:1447, 2015.

Jonathan B. Baker. Taking the error out of "error cost" analysis: What's wrong with antitrust's right. Antitrust Law Journal, 80(1):1-38, 2015.

Samuel R. Berger. Court awarded attorneys' fees: What is reasonable. U. Pa. L. Rev., 126 : 281, 1977.

Albert Choi and Chris William Sanchirico. Should plaintiffs win what defendants lose? litigation stakes, litigation effort, and the benefits of decoupling. The Journal of Legal Studies, 33(2):323-354, 2004.

Albert H. Choi and Kathryn E. Spier. Class actions and private antitrust litigation. Virginia Law and Economics Research Paper, (2019-01), 2019.

Robert D. Cooter and Daniel L. Rubinfeld. Economic analysis of legal disputes and their resolution. Journal of Economic Literature, 27(3):1067-1097, 1989.

Alan Devlin and Michael Jacobs. Antitrust error. Wm. Ef Mary L. Rev., 52:75, 2010.

Frank H. Easterbrook. Limits of antitrust. Tex. L. Rev., 63:1, 1984.

Aaron Edlin, Scott Hemphill, Herbert Hovenkamp, and Carl Shapiro. The actavis inference: Theory and practice. Rutgers UL Rev., 67:585, 2015.

David S. Evans and A. Jorge Padilla. Designing antitrust rules for assessing unilateral practices: a neo-chicago approach. U. Chi. L. Rev., 72:73, 2005.

Giulio Federico, Fiona Scott Morton, and Carl Shapiro. Antitrust and innovation: Welcoming and protecting disruption. Innovation Policy and the Economy, 20(1):125-190, 2020.

Ezra Friedman and Abraham L. Wickelgren. No free lunch: How settlement can reduce the legal system's ability to induce efficient behavior. SMUL Rev., 61:1355, 2008.

Andrew I. Gavil and Harry First. The Microsoft antitrust cases: competition policy for the twenty-first century. MIT Press, 2014. 
Andrew I. Gavil and Steven C. Salop. Probability, presumptions, and evidentiary burdens in antitrust analysis: Revitalizing the rule of reason for exclusionary conduct. forthcoming, University of Pennsylvania Law Review, 2020.

Richard J. Gilbert and David M.G. Newbery. Preemptive patenting and the persistence of monopoly. American Economic Review, 72(3):514-526, 1982.

C. Scott Hemphill. Paying for delay: Pharmaceutical patent settlement as a regulatory design problem. NYU Law Review, 81:1553, 2006.

Erik Hovenkamp. Competition, inalienability, and the economic analysis of patent law. Stanford Technology Law Review, 21:33-73, 2018.

Erik Hovenkamp. Antitrust law and patent settlement design. Harvard Journal of Law $\mathcal{E}$ Technology, 32(2):417, 2019.

Erik Hovenkamp and Jorge Lemus. Proportional restraints in horizontal patent settlements. Working Paper, 2019.

Samuel Issacharoff. Class action conflicts. UC Davis L. Rev., 30:805, 1996.

John Kaplan. Decision theory and the factfinding process. Stan L. Rev., 20:1065, 1967.

Louis Kaplow. Optimal proof burdens, deterrence, and the chilling of desirable behavior. American Economic Review, 101(3):277-80, 2011.

Yoon-Ho Alex Lee and Daniel Klerman. The priest-klein hypotheses: Proofs and generality. International Review of Law and Economics, 48:59-76, 2016.

Michael J. Meurer. The settlement of patent litigation. The RAND Journal of Economics, pages 77-91, 1989.

Nancy Morawetz. Bargaining, class representation, and fairness. Ohio St. LJ, 54:1, 1993.

Richard A. Posner. An economic approach to the law of evidence. Stan. L. Rev., 51:1477, 1998.

George L. Priest and Benjamin Klein. The selection of disputes for litigation. The Journal of Legal Studies, 13(1):1-55, 1984.

Steven C. Salop. Exclusionary conduct, effect on consumers, and the flawed profit-sacrifice standard. Antitrust Law Journal, 73:311, 2005. 
Steven C. Salop. The evolution and vitality of merger presumptions: A decision-theoretic approach. Antitrust Law Journal, 80(2):269-306, 2015.

Warren F. Schwartz. An overview of the economics of antitrust enforcement. Geo. LJ, 68: 1075, 1979.

Warren F. Schwartz and Abraham L. Wickelgren. Optimal antitrust enforcement: Competitor suits, entry, and post-entry competition. Journal of Public Economics, 95(7-8): 967-972, 2011.

Carl Shapiro. Antitrust limits to patent settlements. RAND Journal of Economics, pages 391-411, 2003.

Kathryn E. Spier. Litigation. Handbook of law and economics, 1:259-342, 2007.

Joel Waldfogel. Reconciling asymmetric information and divergent expectations theories of litigation. The Journal of Law and Economics, 41(2):451-476, 1998.

\section{Appendix: Proofs}

\section{Proof of Proposition 1}

Proof. By differentiating equation (1) from Assumption 1, it follows that

$$
\begin{aligned}
& \frac{\partial \Phi(y \mid \mathbf{x}, w)}{\partial x_{2}}<0<\frac{\partial \Phi(y \mid \mathbf{x}, w)}{\partial x_{1}} \\
& \frac{\partial \Phi(y \mid \mathbf{x}, w)}{\partial w}<0 .
\end{aligned}
$$

Then part (ii) follows immediately from (22), while part (iii) follows from (23). By Assumption 2, it is clear that the signal is unbiased if $x_{1}=x_{2}$, since $f$ is symmetric about $w$. But part $(i i)$ implies the signal must be biased whenever $x_{1} \neq x_{2}$, since any change in the ratio $x_{2} / x_{1}$ will skew the distribution in one direction or the other. This establishes part $(i)$. 


\section{Proof of Proposition 2}

Proof. It is easy to verify that each $i$ 's payoff function is strictly concave. Hence, a best response for firm 1 is characterized by the first order condition

$$
\begin{aligned}
& \frac{\partial u_{1}}{\partial x_{1}}=0 \\
\Longleftrightarrow & \frac{\alpha\left[\alpha x_{1}+(1-\alpha) x_{2}\right]-\alpha^{2} x_{1}}{\left[\alpha x_{1}+(1-\alpha) x_{2}\right]^{2}} v_{1}-1=0 \\
\Longleftrightarrow & (1-\alpha) \alpha v_{1} x_{2}=\left[\alpha x_{1}+(1-\alpha) x_{2}\right]^{2} .
\end{aligned}
$$

Repeating this for firm 2, we obtain

$$
(1-\alpha) \alpha v_{2} x_{1}=\left[\alpha x_{1}+(1-\alpha) x_{2}\right]^{2}
$$

Combining these FOCs, an equilibrium must satisfy $v_{1} x_{2}^{*}=v_{2} x_{1}^{*}$. Then substituting $x_{j}^{*}=$ $\left(v_{j} / v_{i}\right) x_{i}^{*}$ into either FOC and simplifying, we obtain a unique solution

$$
x_{i}^{*}=\frac{(1-\alpha) \alpha v_{i}^{2} v_{j}}{\left[\alpha v_{1}+(1-\alpha) v_{2}\right]^{2}} \text {. }
$$

With this, the equilibrium probability that the plaintiff wins is

$$
\begin{aligned}
p^{*} & =\frac{\alpha x_{1}^{*}}{\alpha x_{1}^{*}+(1-\alpha) x_{2}^{*}} \\
& =\frac{\alpha \times \frac{(1-\alpha) \alpha v_{1}^{2} v_{2}}{\left[\alpha v_{1}+(1-\alpha) v_{2}\right]^{2}}}{\alpha \times \frac{(1-\alpha) \alpha v_{1}^{2} v_{2}}{\left[\alpha v_{1}+(1-\alpha) v_{2}\right]^{2}}+(1-\alpha) \times \frac{(1-\alpha) \alpha v_{1} v_{2}^{2}}{\left[\alpha v_{1}+(1-\alpha) v_{2}\right]^{2}}} \\
& =\frac{(1-\alpha) \alpha^{2} v_{1}^{2} v_{2}}{(1-\alpha) \alpha^{2} v_{1}^{2} v_{2}+(1-\alpha)^{2} \alpha v_{1} v_{2}^{2}} \\
& =\frac{\alpha v_{1}}{\alpha v_{1}+(1-\alpha) v_{2}} .
\end{aligned}
$$

By inspection, we have $x_{i}^{*}=v_{i} p^{*}\left(1-p^{*}\right)$ for each $i$, as desired. 


\section{Proof of Proposition 5}

Proof. The result follows from the proof of Proposition 2, but with the modification that now impose $v_{1}=v_{2}=\tau+\delta$, which reflects that the court's decision will only determine whether party 2 has to pay $\tau+\delta$ to party 1 . The desired results then follow immediately from the expressions given for $x_{i}^{*}$ and $p^{*}$ in Proposition 2, since the latter's proof is valid for any positive values of $v_{1}$ and $v_{2}$.

\section{Proof of Proposition 7}

Proof. Part (i): When litigation expenditures are symmetric, it follows from Assumptions 1 and 2 that the signal density $\phi(y \mid \mathbf{x}, w)$ reduces to $f(y \mid w)$, which is symmetric about $w$ and depends only on $|y-w|$. Then $\widetilde{\eta}$ is pinned down by the equation

$$
\mathrm{P}_{\rho}\left\{w<0 \mid y=\widetilde{\eta}, x_{1}=x_{2}\right\}=\frac{\int_{-\infty}^{0} \rho(w) f(\widetilde{\eta} \mid w) d w}{\int_{-\infty}^{\infty} \rho(w) f(\widetilde{\eta} \mid w) d w}=\frac{1}{2} .
$$

Rearranging and simplifying this equation, we obtain

$$
\int_{-\infty}^{0} \rho(w) f(\widetilde{\eta} \mid w) d w=\int_{0}^{\infty} \rho(w) f(\widetilde{\eta} \mid w) d w
$$

By the symmetry of $\rho$ and $f$ (Assumptions 2,3), the product $\rho(w) f(w \mid \mu)=\rho(w) f(\mu \mid w)$ is symmetric about $\mu$. Therefore, if $\mu=0$ then the two sides will be equal iff $\tilde{\eta}=0$; but if $\mu<0$ (resp. $\mu>0$ ), then equality requires that $\widetilde{\eta}>0$ (resp. $\widetilde{\eta}<0$ ), as desired. We further note that, in the special case $\rho(w)=f(w \mid \mu)$, setting $\widetilde{\eta}=-\mu$ and using $f(a \mid b)=f(a-b \mid 0)=$ $f(b-a \mid 0)$, we find

$$
\rho(w) f(\widetilde{\eta} \mid w)=f(w \mid \mu) f(-\mu \mid w)=f(w-\mu \mid 0) f(-\mu-w \mid 0)=f(w-\mu \mid 0) f(w+\mu \mid 0),
$$

which is symmetric about zero. Therefore setting $\widetilde{\eta}=-\mu$ satisfies (25) in this case.

Part (ii): Suppose that the firms play equilibrium strategies $\mathbf{x}_{\eta}^{*}$, which are themselves conditional on the presumption, as established in Proposition 6. In this case, the optimal presumption $\eta^{*}$ is pinned down by the equation

$$
\mathrm{P}_{\rho}\left\{w<0 \mid y=\eta^{*}, \mathbf{x}=\mathbf{x}_{\eta^{*}}^{*}\right\}=\frac{\int_{-\infty}^{0} \rho(w) \phi\left(\eta^{*} \mid \mathbf{x}_{\eta^{*}}^{*}, w\right) d w}{\int_{-\infty}^{\infty} \rho(w) \phi\left(\eta^{*} \mid \mathbf{x}_{\eta^{*}}^{*}, w\right) d w}=\frac{1}{2}
$$


Rearranging this equation, we obtain

$$
\int_{-\infty}^{0} \rho(w) \phi\left(\eta^{*} \mid \mathbf{x}_{\eta^{*}}^{*}, w\right) d w=\int_{0}^{\infty} \rho(w) \phi\left(\eta^{*} \mid \mathbf{x}_{\eta^{*}}^{*}, w\right) d w
$$

Differentiating $\Phi$ to obtain $\phi$, we find that $\phi(y \mid \mathbf{x}, w)=\Gamma(y \mid \mathbf{x}, w) \times f(y \mid w)$, where

$$
\Gamma(y \mid \mathbf{x}, w) \equiv \frac{x_{1} x_{2}}{\left(F(y \mid w) x_{1}+[1-F(y \mid w)] x_{2}\right)^{2}}
$$

It is straightforward to verify that

$$
\Gamma(y \mid \mathbf{x}, w) \lesseqgtr 1 \Longleftrightarrow \frac{x_{2}}{x_{1}} \gtreqless\left(\frac{F(y \mid w)}{1-F(y \mid w)}\right)^{2} .
$$

Since $x_{2, \eta}^{*}>x_{1, \eta}^{*}$ (for any $\left.\eta\right)$, this implies that $\Gamma\left(\eta \mid \mathbf{x}_{\eta}^{*}, w\right)<1$ whenever $\eta<w$, while $\Gamma\left(\eta \mid \mathbf{x}_{\eta}^{*}, w\right) \geq 1$ whenever $\eta$ is sufficiently larger than $w$. Then, using (25) from Part (i) above, it follows that

$$
\int_{-\infty}^{0} \rho(w) \Gamma\left(\widetilde{\eta} \mid \mathbf{x}_{\widetilde{\eta}}^{*}, w\right) f(\widetilde{\eta} \mid w) d w>\int_{0}^{\infty} \rho(w) \Gamma\left(\widetilde{\eta} \mid \mathbf{x}_{\widetilde{\eta}}^{*}, w\right) f(\widetilde{\eta} \mid w) d w
$$

Here we have inserted $\Gamma\left(\widetilde{\eta} \mid \mathbf{x}_{\tilde{\eta}}^{*}, w\right)$ into the integrands on both sides of equation (25). This breaks the equality in (25), because $\Gamma$ adds weight to the LHS integral while removing weight from the RHS integral. However, if we replaced $\Gamma\left(\widetilde{\eta} \mid \mathbf{x}_{\tilde{\eta}}^{*}, w\right) f(\widetilde{\eta} \mid w)$ with $\Gamma\left(\eta^{*} \mid \mathbf{x}_{\eta^{*}}^{*}, w\right) f\left(\eta^{*} \mid w\right)$, then the two sides above would have to be equal; this follows immediately from equation (28) and the definition of $\Gamma$. Therefore $\widetilde{\eta}$ is not large enough to satisfy (28), ergo $\eta^{*}>\widetilde{\eta}$.

Part (iii): Now assume $\mu=0$, so that part $(i)$ implies $\widetilde{\eta}=0$. In this case, consider the specific case where the true welfare effect is $w=\widetilde{\eta}=0$. We will show that the median signal (conditional on equilibrium expenditures) in this case coincides with $\eta_{0}^{*}$. If true, then $\eta_{0}^{*}$ is 
pinned down by

$$
\begin{gathered}
\Phi\left(\eta^{*} \mid \mathbf{x}_{\eta_{0}^{*}}^{*}, w=0\right)=\frac{1}{2} \\
\Longleftrightarrow \quad \frac{F\left(\eta_{0}^{*} \mid 0\right) x_{1, \eta_{0}^{*}}^{*}}{F\left(\eta_{0}^{*} \mid 0\right) x_{1, \eta_{0}^{*}}^{*}+\left[1-F\left(\eta_{0}^{*} \mid 0\right)\right] x_{2, \eta_{0}^{*}}^{*}}=\frac{1}{2} \\
\Longleftrightarrow \quad \frac{F\left(\eta_{0}^{*} \mid 0\right) v_{1}}{F\left(\eta_{0}^{*} \mid 0\right) v_{1}+\left[1-F\left(\eta_{0}^{*} \mid 0\right)\right] v_{2}}=\frac{1}{2} \\
\quad F\left(\eta_{0}^{*} \mid 0\right)=\frac{v_{2}}{v_{1}+v_{2}},
\end{gathered}
$$

which is the desired expression. To confirm that value of $\eta_{0}^{*}$ must be correct, note that if (and only if) the court observes $y<\eta_{0}^{*}$, then we can conclude the true value of $w$ is most likely negative, because: (a) $\rho$ is symmetric about zero; and (b) under equilibrium expenditures, every positive (resp. negative) value of $w$ has a median signal value that is strictly larger (resp. smaller) than $\eta_{0}^{*}$. 